\title{
Proteomic profiling of bovine M. longissimus lumborum from Crossbred Aberdeen Angus and Belgian Blue sired steers varying in genetic merit for carcass weight ${ }^{1}$
}

\author{
Sarah M. Keady, ${ }^{\dagger}$ David A. Kenny, ${ }^{*}$ Kay Ohlendieck, $\uparrow$ Sean Doyle, $\uparrow$ M. G. Keane, $\$$ and Sinéad M. Waters*2 \\ *Animal and Bioscience Research Department, Animal and Grassland Research and Innovation Centre, \\ Teagasc, Dunsany, Co. Meath, Ireland; †Department of Biology, National University of Ireland, Maynooth, Co. Kildare, \\ Ireland; and $\ddagger$ Teagasc, Animal and Grassland Research and Innovation Centre, Grange, Dunsany, Co. Meath, Ireland
}

ABSTRACT: Bovine skeletal muscle is a tissue of significant value to the beef industry and global economy. Proteomic analyses offer the opportunity to detect molecular mechanisms regulating muscle growth and intramuscular fat accumulation. The current study aimed to investigate differences in protein abundance in skeletal muscle tissue of cattle from two breeds of contrasting maturity (early vs. late maturing), adiposity, and muscle growth potential, namely, Belgian Blue $(\mathrm{BB}) \times$ Holstein Friesian and Aberdeen Angus $(\mathrm{AA}) \times$ Holstein Friesian. Twenty AA $(n=10)$ and BB $(n=10)$ sired steers, the progeny of sires of either high or low genetic merit, expressed as expected progeny difference for carcass weight $\left(\mathrm{EPD}_{\mathrm{cwt}}\right)$, and bred through $\mathrm{AI}$, were evaluated as 4 genetic groups, BB-High, BB-Low, AA-High, and AA-Low ( $n=5$ per treatment). Chemical composition analysis of $M$. longissimus lumborum showed greater protein and moisture and decreased lipid concentrations for BB-sired compared with AA-sired steers. To investigate the effects of both sire breed and $\mathrm{EPD}_{\mathrm{cwt}}$ on $M$. longissimus lumborum, proteomic analysis was performed using 2-dimensional difference gel electrophoresis followed by mass spectrometry. Proteins were identified from their peptide sequences, using the National Center for Biotechnology Information (NCBI) and Swiss-prot databases. Metabolic enzymes involved in glycolysis (glycogen phosphorylase, phosphoglycerate mutase) and the citric acid cycle (aconitase 2, oxoglutarate dehydrogenase) were increased in AA- vs. BB-sired steers. Expression of proteins involved in cell structure, such as myosin light chain isoforms and troponins I and $\mathrm{T}$, were also altered due to sire breed. Furthermore, heat shock protein $\beta-1$ and peroxiredoxin 6 , involved in cell defense, had increased abundance in muscle of AA-sired relative to BB-sired steers. Protein abundance of glucose-6-phosphate isomerase, enolase-3, and pyruvate kinase was greater in AA-sired animals of High compared with Low $\mathrm{EPD}_{\text {cwt }}$. Changes in the expression of these proteins were supported by gene expression analysis using quantitative real-time PCR. This information will aid in our understanding of genetic influences controlling muscle growth and fat accumulation and could contribute to future breeding programs to increase lean tissue gain of beef cattle.

Key words: cattle, growth, proteomics, skeletal muscle, glycolysis

(C) 2013 American Society of Animal Science. All rights reserved.

J. Anim. Sci. 2013.91:654-665

doi: $10.2527 /$ jas2012-5850

\section{INTRODUCTION}

\footnotetext{
${ }^{1}$ This study was funded by the Teagasc Walsh Fellowship Scheme. The authors wish to acknowledge the technical help and assistance of Edel Mullen, Stephen Carberry, and Caroline Batchelor in National University of Ireland Maynooth and Brian Campion at the Teagasc, Animal and Grassland Research and Innovation Centre, Grange, for providing access to production data. Image analysis and liquid chromatography-mass spectrometry instrumentation was funded by the Health Research Board and the Higher Education Authority, respectively. The authors have declared that no conflict of interest exists.

${ }^{2}$ Corresponding author: sinead.waters@teagasc.ie

Received September 12, 2012.

Accepted December 22, 2012.
}

Bovine skeletal muscle is a tissue of significant economic importance worldwide. Genetic evaluations for a range of economically important performance traits across all of the main cattle breeds in Ireland are undertaken by the Irish Cattle Breeding Federation. Genetic merit for carcass growth rate, an important commercial trait reflecting lifetime growth, is estimated using a multitrait animal model and is 
expressed as the EPD for carcass weight (EPD cwt$_{\text {; }}$; Campion et al., 2009a). Both sire breed type and $\mathrm{EPD}_{\text {cwt }}$ influence carcass characteristics, including yield and quality of saleable meat from cattle (Campion et al., 2009a,b; Keane and Moloney, 2010; Keane et al., 2011). Belgian Blue (BB) is a late-maturing breed noted for its exaggerated muscular growth and very lean meat deposition (Fiems et al., 2013), whereas Aberdeen Angus (AA), an early-maturing breed, is renowned for greater levels of marbling fat in muscle, which is favorably associated with tenderness and flavor of beef (Kuber et al., 2004).

A number of studies to date have investigated the physical and physiological differences in animals varying in $\mathrm{EPD}_{\text {cwt }}$ (Crews et al., 2004; Keane et al., 2011). In addition, Bernard et al. (2009) examined the effects of genetic selection in favor of high muscle growth on global gene expression in muscle tissue of young Charolais bulls. Data from our own group show that both sire breed and genetic merit for carcass weight affect the expression of genes regulating the somatotropic axis in muscle of cattle (Keady et al., 2011), with greater gene expression of IGF-1 and reduced transcript abundance of IGFBP3 in muscle potentially having a role in increased muscle growth. Whereas transcriptomic studies have been fundamental in the establishment of the molecular mechanisms regulating important traits in cattle (McCabe et al., 2012; Zhao et al., 2012), mRNA expression does not always reflect corresponding proteomic abundance (Rogers et al., 2008). Consequently, proteomic studies examining large numbers of proteins simultaneously, including their posttranslational modifications (Rogers et al., 2008), offer a snapshot of the functional molecules of the cells under investigation.

Protein expression of skeletal muscle in both sheep (Hamelin et al., 2006) and cattle (Talamo et al., 2003; Bouley et al., 2004, 2005) has been examined. To the knowledge of the authors, few data exist on the effect of either breed or genetic merit for carcass growth on global protein abundance in bovine muscle. Therefore, the objective of this study was to determine the effect of 1) sire breed and 2) sire $\mathrm{EPD}_{\mathrm{cwt}}$ on the expression of proteins in $M$. longissimus lumborum in AA- and BB-sired cattle using 2-dimensional difference gel electrophoresis (2D-DIGE) and mass spectrometry.

\section{MATERIALS AND METHODS}

All procedures were performed under license in accordance with European Community Directive 86609-EC. Animals were slaughtered in a licensed abattoir (Meadow Meats, Rathdowney, Co. Laois, Ireland).

\section{Experimental Design}

This study utilized $M$. longissimus lumborum samples collected at slaughter from a larger study by Campion et al. (2009a). Briefly, in that study, steer progeny $(n=114)$ of Holstein-Friesian (HF) dairy cows sired by bulls of 2 contrasting beef breeds (AA and BB) were used. Within each sire breed, sires were selected on the basis of EPD for carcass weight $\left(\mathrm{EPD}_{\mathrm{cwt}}\right)$ and classified as either High or Low. There were 32 steer progeny of High $\mathrm{EPD}_{\mathrm{cwt}}$ sires and 24 of Low EPD sires. For BB there were 31 progeny of High and 27 of Low EPD ${ }_{\text {cwt }}$ sires.

There was no difference between the dams of the various genetic groups in estimated genetic merit for beef production and carcass weight (Campion et al., $2009 \mathrm{~b}$ ). The finishing diet consisted of a total mixed ration with a grass-silage:concentrate ratio of 30:70 on a DM basis (Campion et al., 2009a). For the current study, a representative subset of 20 steers was selected at slaughter in a $2($ sire breed $) \times 2\left(\right.$ sire $\left.\mathrm{EPD}_{\mathrm{cwt}}\right)$ factorial design ( $n=5$ per treatment), generating 4 genetic groups of AA-High, AA-Low, BB-High, and BB-Low based on the original blocking criteria of Campion et al. (2009a). The 20 animals represented the progeny of 12 sires (AA, $n=6$, and $\mathrm{BB}, n=6$ ) with no over dominance of any particular sire within group. Mean values for the subgroups used in our study for the main outcome traits were similar to that of Campion et al. (2009a; i.e., mean animal slaughter weight for AA was $583 \mathrm{~kg}$ and for BB was $600 \mathrm{~kg}$, whereas ADG for AAHigh vs. Low were $0.64 \mathrm{~kg}$ and for $\mathrm{BB}$ were $0.71 \mathrm{~kg}$ ). As crossbred BB animals were employed in this study, it must be noted that they were heterozygous for the myostatin null mutation.

\section{Chemical Composition of M. longissimus lumborum}

At $48 \mathrm{~h}$ after slaughter, steaks were cut from the $M$. longissimus lumborum between the 6th and 10th ribs, vacuum packaged immediately, frozen, and used for subsequent chemical analysis. Intramuscular fat and moisture concentrations were determined from thawed Longissimus thoracis et lumborum using the Smart System 5 microwave moisture drying oven and NMR Smart Trac Rapid Fat analyzer (CEM Microwave Technology Ltd., Buckingham, UK), using AOAC Official Methods 992.15 (1990). Protein concentration was determined using a LECO FP328 (LECO Corp., St. Joseph, MI) protein analyzer on the basis of the Dumas method and according to AOAC Official Method 992.15 (1990). 


\section{Tissue Collection, Extraction}

\section{of Muscle Proteins, and 2D-DIGE}

Campion et al. (2009a) reported that LM area and LM area per unit carcass weight were greater for Belgian Blue $\times$ Holstein Friesian $(\mathbf{B B}-\mathbf{H F})$ compared with Aberdeen Angus $\times$ Holstein Friesian $(\mathbf{A A}-\mathbf{H F})$ steers and also for AA animals sired by bulls with High compared with Low $\mathrm{EPD}_{\mathrm{cwt}}$. Specifically, M. longissimus lumborum is of high economic and commercial value. For these reasons M. longissimus lumborum was selected for proteomic analysis in the current study. Samples of M. longissimus lumborum were harvested from animals at slaughter and washed in sterile Dulbecco's PBS (Sigma-Aldrich Ireland Ltd., Dublin, Ireland). Samples were snap frozen at $-80^{\circ} \mathrm{C}$ in liquid nitrogen within $20 \mathrm{~min}$ of slaughter. A sample was also stored at $-80^{\circ} \mathrm{C}$ for quantitative realtime PCR (qRT-PCR) validation analysis. Because of differences in inter- and intramuscular fat in the muscle tissue from AA- vs. BB-sired animals, care was taken to collect lean muscle tissue only for protein and mRNA isolation while avoiding inter- and intramuscular fat.

Protein extraction and 2D-DIGE were performed as described by Mullen et al. (2011). Frozen muscle (100 mg) was weighed and crushed into a fine powder using a mortar and pestle and placed in $7 M$ urea, $2 M$ thiourea, $1 \%(\mathrm{wt} / \mathrm{vol})$ dithiothreitol (DTT), 4\% (wt/vol) 3-[(cholamidopropyl) dimethylammonio] propanesulfonic acid (CHAPS), and $8 \%$ (vol/vol) ampholytes ( $\mathrm{pH} 3$ to 10; Bio-Rad Laboratories Inc., Hercules, CA). To avoid protein degradation, protease inhibitors (Roche, Clarecastle, Co., Clare, Ireland) were added. Samples were shaken vigorously at $4^{\circ} \mathrm{C}$ for 150 min before centrifugation at $10,000 \times \mathrm{g}$ for $20 \mathrm{~min}$ at $4^{\circ} \mathrm{C}$. Bradford colorimetric protein assays (Bio-Rad Laboratories Inc.) were performed to determine protein concentration using BSA as a standard. Immobiline DryStrips (GE Healthcare Biosciences, Buckinghamshire, $\mathrm{UK}), 24 \mathrm{~cm}$, covering a $\mathrm{pH}$ range of 3 to 10 were rehydrated overnight in $500 \mu \mathrm{g}$ of sample up to a volume of $450 \mu \mathrm{L}$ of rehydration buffer [ $8 M$ urea, $0.5 \%$ (vol/vol) CHAPS, $0.2 \%$ (wt/vol) DTT, and $0.2 \%$ (vol/vol) ampholytes ( $\mathrm{pH}$ 3 to 10; Bio-Rad Laboratories)]. DeStreak reagent (GE Healthcare Biosciences) was added to the sample solution to stabilize thiol groups and prevent nonspecific oxidation. Isoelectric focusing was performed in an Ettan IPGphor 3 Isoelectric Focusing Unit (GE Healthcare Biosciences), and the following voltage/time program was used: $100 \mathrm{~V}$ for $120 \mathrm{~min}, 500 \mathrm{~V}$ for $90 \mathrm{~min}, 1,000 \mathrm{~V} 60 \mathrm{~min}, 2,000$ $\mathrm{V}$ for $60 \mathrm{~min}, 4,000 \mathrm{~V}$ for $60 \mathrm{~min}, 6,000 \mathrm{~V}$ for $120 \mathrm{~min}$, $8,000 \mathrm{~V}$ for $150 \mathrm{~min}, 500 \mathrm{~V}$ for $240 \mathrm{~min}$, and 8,000 V for $300 \mathrm{~min}$. After focusing, strips were equilibrated for $15 \mathrm{~min}$ in $1 \%$ (wt/vol) DTT followed by $15 \mathrm{~min}$ in $2.5 \%$ (wt/vol) iodoacetamide. After equilibration, proteins were separated on a $12 \%$ polyacrylamide gel using the DALTtwelve separation unit (GE Healthcare Biosciences).

\section{Gel Staining and Image Analysis}

For DIGE analysis, Cy3 and Cy5 dyes were reconstituted as a stock solution of $1 \mathrm{~m} M$ in fresh dimethylformamide. The stock solution was diluted to a working solution of $0.2 \mathrm{mM}$ before protein labeling. Individual samples $(50 \mu \mathrm{g}$ protein $)$ were minimally labeled with 200 pmol of Cy3 working solution (Karp and Lilley, 2005). A pooled sample consisting of equal quantities of protein from all replicates used in the experiment were labeled at a ratio of $200 \mathrm{pmol}$ of Cy5 working solution to $50 \mu \mathrm{g}$ of muscle protein. All samples were labeled with the appropriate amount of dye at $\mathrm{pH} 8.5$ and then incubated on ice in the dark for $30 \mathrm{~min}$ (Mullen et al., 2011). Ruthenium (II) tris bathophenanthroline disulfonate (RuBPS), a well-established fluorescent dye for protein staining, was applied for $6 \mathrm{~h}$, followed by destaining using $40 \%$ (vol $/ \mathrm{vol})$ ethanol and $10 \%$ (vol $/ \mathrm{vol})$ acetic acid for $15 \mathrm{~h}$. Reference gels containing the pooled sample were generated for spot picking and stained with Coomassie Brilliant Blue (Doran et al., 2006). Imagemaster platinum analysis software v5.0 was used for imaging gels using a Typhoon variable mode image scanner (GE Healthcare Biosciences). Progenesis Samespots V3.2.3 software (NonLinear Dynamics, Newcastle upon Tyne, UK) was used for the detection of protein spots, background subtraction and detection of proteins with statistically significant differences across groups. Before analysis of individual gels, a single reference gel, representing electrophoretically separated proteins from muscle tissue from all animals in the study, was analyzed and further matched and normalized with non-gel spots manually filtered out on the basis of spot volume (Donoghue et al., 2010; Mullen et al., 2011). Differentially expressed protein spots $(P<0.05)$ between AA and BB were classified as biologically significant with a fold change greater than 1.9 and were selected for tryptic digestion from gels stained with Coomassie Brilliant Blue G-250. At a fold change of greater than 1.9 , no difference in protein abundance was identified between High and Low steers for EPD ${ }_{\text {cwt }}$. However, in complex biological systems physiological changes are often controlled by larger numbers of small fluctuations in signaling networks rather than a small number of large changes (Amaral et al., 2004). Therefore, a 1.5-fold induction in protein abundance was selected as a cutoff between High- and Low-sired steers for EPD (AA-High vs. AA-Low; BB-High vs. BB-Low), which is consistent with findings of previous research in relation to the High and Low for growth rate (Bernard et al., 2009).

\section{Protein Spot Isolation and Identification Using Mass Spectrometry}

Mass spectrometric identification of the muscle proteins of interest was performed as previously 
described (O'Connell and Ohlendieck, 2009). In brief, protein spots were carefully excised using a sterile pipette tip and digested using trypsin (Promega, Southampton, UK) overnight at $37^{\circ} \mathrm{C}$. The solution was removed, and 30\% (vol/vol) acetonitrite (ACN) $/ 0.2 \%$ (vol/vol) trifluoroacetic acid (TFA) was added to each gel plug and incubated for $10 \mathrm{~min}$ at $37^{\circ} \mathrm{C}$, followed by $60 \%$ (vol $/ \mathrm{vol}$ ) ACN $/ 0.2 \%$ (vol $/ \mathrm{vol}$ ) TFA for $10 \mathrm{~min}$ at $37^{\circ} \mathrm{C}$. The solution was dried overnight, and $10 \mu \mathrm{L}$ of $0.1 \%$ ( $\mathrm{vol} / \mathrm{vol}$ ) formic acid were added to the protein pellet. Identification of proteins was performed with a Model 6340 Ion Trap LC/MS (Agilent Technologies, Dublin, Ireland). Proteins were identified from their peptide sequences, searching on the National Center for Biotechnology Information (NCBI; http://www.ncbi.nlm. nih.gov) database. This database was interrogated using the MASCOT search engine (http://www.matrixscience. com; Matrix Science, London, UK) with comparison with mammalian databases allowing up to one single trypsin missed cleavage.

\section{Validation of Protein Expression using qRT-PCR}

Ideally, validation of DIGE results of candidate proteins should have been conducted using Western blotting. However, in the current study, we experienced some technical issues with the Western blotting procedure. We did, however, validate the proteomic data generated using a qRT-PCR approach, and whereas some studies have shown a lack of correlation between the outcomes of these 2 techniques (Greenbaum et al., 2003), in the current study high positive correlation coefficients between gene transcript and protein data were observed.

For the purpose of validation of proteomic data, 6 proteins, 3 (HSPB1, PRDX6, and MYL1) found to be differentially expressed in the AA-sired compared with the BB-sired steers and 3 (ENO3, GPI, and PKM2) that were shown to be differentially expressed in High and Low $\mathrm{EPD}_{\text {cwt }}$ in muscle tissue of AA, were targeted using qRTPCR analysis. Total RNA was isolated from approximately $40 \mathrm{mg}$ of the same muscle tissue used for protein analysis using TRIzol reagent and chloroform (Sigma-Aldrich Ireland). Tissue samples were homogenized using a tissue lyser (Qiagen, Manchester, UK), after which the RNA was precipitated using isopropanol. Samples were then treated with RQ1 RNase-free DNase (Promega UK, Southhampton, UK), according to the manufacturer's instructions, to remove any contaminating genomic DNA. The quantity of the RNA isolated was determined by measuring the absorbance at $260 \mathrm{~nm}$ using a Nanodrop spectrophotometer ND-1000 (Thermo Scientific, Wilmington, DE). The RNA quality was assessed on the Agilent Bioanalyser 2100 using the RNA 6000 Nano Lab Chip kit (Agilent Technologies). The RNA quality was verified by ensuring all RNA samples had an absorbance $\left(\mathrm{A}_{260 / 280}\right)$ of between 1.8 and 2 . The RNA samples with $28 \mathrm{~S} / 18 \mathrm{~S}$ ratios ranging from 1.8 to 2.0 and an RNA integrity number (RIN) of between 8 and 10 were deemed high quality.

Total RNA $(1 \mu \mathrm{g})$ was reverse transcribed into cDNA using a High Capacity cDNA Reverse Transcription Kit (Applied Biosystems, Foster City, CA) using the Multiscribe reverse transcriptase according to manufacturer's instructions. Samples were stored at $-20^{\circ} \mathrm{C}$ for subsequent analyses. To select stable reference genes for the muscle tissue being investigated, analysis of putative reference genes was performed using the geNorm version 3.4 Excel software (Microsoft, Redmond, WA). The cycle threshold $(\mathbf{C t})$ values were transformed to relative quantities using the comparative delta $\mathrm{Ct}\left(\mathbf{2}^{-}\right.$ $\Delta \mathbf{C T}$ ) method to facilitate the calculation of the $\mathrm{M}$ value within the geNorm software. A gene was considered to be sufficiently stable if an $M$ value of less than 1.5 was generated. Within this range of parameters, $\beta$-actin (ACTB), glyceraldehydes 3-phosphate dehydrogenase $(\boldsymbol{G A P D H})$ and ribosomal protein SP (RPS9) were selected as suitable reference genes for this study. All primer sets (listed in Table 4; see Results section) to amplify reference and specific target genes (ENO3, GPI, and PKM2) were designed using the Web-based software program Primer 3 (http://frodo.wi.mit.edu/primer3/) and were obtained from a commercial supplier (Sigma-Aldrich Ireland).

After reverse transcription, cDNA quantity was determined and standardized to the required concentration for $\mathrm{qPCR}$. Triplicate $20 \mu \mathrm{L}$ reactions were performed in 96-well optical reaction plates (Applied Biosystems, Warrington, UK) containing $1 \mu \mathrm{L} \mathrm{cDNA}(10$ to $50 \mathrm{ng}$ of RNA equivalents), $10 \mu \mathrm{L}$ Fast SYBR Green PCR Master Mix (Applied Biosystems), $8 \mu \mathrm{L}$ nucleasefree $\mathrm{H}_{2} \mathrm{O}$, and $1 \mu \mathrm{L}$ forward and reverse primers (250 to $1,000 \mathrm{n} M$ per primer). Assays were performed using the ABI 7500 Fast qPCR System (Applied Biosystems) with the following cycling parameters: $95^{\circ} \mathrm{C}$ for $20 \mathrm{~s}$ and 40 cycles of $95^{\circ} \mathrm{C}$ for $3 \mathrm{~s}, 60^{\circ} \mathrm{C}$ for $30 \mathrm{~s}$ followed by amplicon dissociation $\left(95^{\circ} \mathrm{C}\right.$ for $15 \mathrm{~s}, 60^{\circ} \mathrm{C}$ for 1 min, $95^{\circ} \mathrm{C}$ for $15 \mathrm{~s}$, and $60^{\circ} \mathrm{C}$ for $15 \mathrm{~s}$ ). Amplification efficiencies were determined for all target and reference genes using the formula $\mathrm{E}=10^{(-1 / \mathrm{slope})}$, with the slope of the linear curve of $\mathrm{Ct}$ values plotted against the $\log$ dilution (Higuchi et al., 1993).

Only primers with PCR efficiencies between $90 \%$ and $110 \%$ were used. The software package GenEx 5.2.1.3 (MultiD Analyses AB, Gothenburg, Sweden) was used for efficiency correction of the raw $\mathrm{Ct}$ values, interplate calibration based on a calibrator sample included on all plates, averaging of replicates, normalization to the reference gene, and the calculation of quantities relative to the greatest $\mathrm{Ct}$. Expression of each target 
gene was normalized to the reference genes, and relative differences in gene expression were calculated using the $2^{-\Delta \mathrm{CT}}$ method (Livak and Schmittgen, 2001).

\section{Statistical Analysis}

Data relating to the chemical composition of the muscle and key performance data from Campion et al. $(2009 a, b)$ were checked for adherence to normality using the UNIVARIATE procedure of statistical analysis software (SAS Inst. Inc., Cary, NC). Nonnormally distributed data were transformed, as appropriate, by raising to the power of $\lambda$ (TransReg procedure). Data were analyzed using mixed models ANOVA (PROC MIXED). Sire breed and genetic merit for growth potential were included as fixed effects in the statistical model together with the interaction term, where appropriate. Sire was included as a random effect. The Tukey critical difference test was performed to determine the existence of statistical differences between treatment mean values.

Progenesis SameSpots analysis (SSA) was used to identify proteins of interest as described by Donoghue et al. (2010) and Mullen et al. (2011). The gel images were placed into groups (AA, BB, AA-High, and AALow), and analysis was carried as follows: AA vs. BB, AA-High vs. AA-Low, and BB-High vs. BB-Low. The Progenesis Samespots software uses a 1-way ANOVA test, and therefore, the interaction term could not be tested. For sire breed comparison, gel images from both breeds were matched to a single reference gel image. Power analysis was performed independently for each protein spot, with changes displaying a power of $<0.8$ being removed from the analysis. Statistical analysis of the relative abundance of each matched protein spot across the data sets was performed using Student's $t$ test. Additionally, $t$ tests between mean protein differences, with a $P$-value of $>0.05$, were removed from analysis.

For qRT-PCR analysis, a mixed model ANOVA (PROC MIXED, SAS) was conducted to determine the

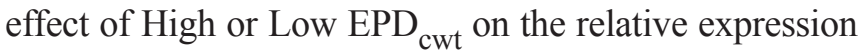
of each gene measured. The Tukey critical difference test was performed to determine the existence of statistical difference between the treatment groups. Fold changes in gene expression between the High and Low growth rates were determined. Spearman correlation coefficients were calculated to determine associations between the expression of proteins and genes found to be differentially expressed between High and Low for $\mathrm{EPD}_{\text {cwt }}$ in AA muscle tissue using the CORR procedure of SAS.

\section{RESULTS}

\section{Chemical Analysis of LM}

There was a difference in the chemical composition of the muscle between breeds (Table 1), with BB having greater $(P<0.001)$ protein and moisture content and a decreased $(P<0.001)$ lipid concentration compared with AA. There was no effect $(P>0.05)$ of $\mathrm{EPD}_{\mathrm{cwt}}$ or sire breed $\times \mathrm{EPD}_{\mathrm{cwt}}$ interaction on $\mathrm{LM}$ composition after chemical analysis.

\section{Effect of Sire Breed on Protein Abundance}

After scanning with an Amersham Typhoon Trio variable imager and with the assistance of Progenesis 2D analysis software, a total of 612 two-dimensional spots were detectable on the reference gel. Twenty-one protein spots, relating to 16 protein products, were identified as different $(P<0.005)$ in their abundance across sire breed, with fold changes larger than 1.9 (Figure 1 and Table 2). To investigate the functional significance of the identified differentially expressed proteins, Ingenuity Pathway Analysis (IPA) software (IPA V9.0; Ingenuity Systems, Mountain View, CA, http://www.ingenuity.com) was used. Overall, the top canonical pathway identified was glycolysis/gluconeogenesis, with three proteins [glycogen phosphorylase (PYGM), phosphoglycerate mutase 2 (PGAM2), and aldolase A (ALDOA)] within the pathway activated. The second canonical pathway identified as activated was the citric cycle, with enzymes aconitase-2 (ACO2) and 2-oxoglutarate dehydrogenase (OGDH) identified as greater in abundance in AA compared with $\mathrm{BB}$. The third canonical pathway was the protein kinase

Table 1. Effect of sire breed (B) and EPD for carcass weight $\left(\mathrm{EPD}_{\mathrm{cwt}}\right)$ on the chemical composition (expressed as a percentage of $100 \%$ ) of $M$. longissimus lumborum at slaughter

\begin{tabular}{|c|c|c|c|c|c|c|c|c|c|}
\hline \multirow[b]{2}{*}{ Variable } & \multicolumn{3}{|c|}{$\mathrm{B}^{1}$} & \multicolumn{3}{|c|}{$\mathrm{EPD}_{\mathrm{cwt}}{ }^{2}$} & \multicolumn{3}{|c|}{$P$-value } \\
\hline & AA-HF & BB-HF & $\mathrm{SED}^{3}$ & High & Low & $\mathrm{SED}^{3}$ & B & $\mathrm{EPD}_{\mathrm{cwt}}$ & $\mathrm{B} \times \mathrm{EPD}_{\mathrm{cwt}}$ \\
\hline Protein & $22.22^{\mathrm{a}}$ & $23.12^{b}$ & 0.16 & 22.76 & 22.57 & 0.16 & $* * *$ & 0.25 & 0.88 \\
\hline Moisture & $71.39^{\mathrm{a}}$ & $73.29^{b}$ & 0.27 & 72.39 & 72.30 & 0.27 & $* * *$ & 0.73 & 0.64 \\
\hline Fat & $6.01^{\mathrm{a}}$ & $2.99^{b}$ & 0.37 & 4.39 & 4.62 & 0.37 & $* * *$ & 0.53 & 0.84 \\
\hline
\end{tabular}

${ }^{\mathrm{a}, \mathrm{b}}$ Least squares means within a row with different superscript $\operatorname{differ}(P<0.05) ; * P<0.05, * * P<0.01, * * * P<0.001$.

${ }^{1} \mathrm{AA}-\mathrm{HF}=$ Aberdeen Angus $\times$ Holstein Friesian; BB-HF $=$ Belgian Blue $\times$ Holstein Friesian.

${ }^{2} \mathrm{High}=$ high for $\mathrm{EPD}_{\mathrm{cwt}}$; Low $=$ low for $\mathrm{EPD}_{\mathrm{cwt}}$.

${ }^{3} \mathrm{SED}=\mathrm{SE}$ of the difference. 
A signaling (PKA) pathway, with proteins myosin light chain 1 (MYL1), myosin light chain, phosphorylatable (MYLPF), PYGM, and troponin I (TNNI2) differing in abundance across breed. Finally, the fourth canonical pathway identified was the pentose phosphate pathway, with ALDOA greater and phosphoglucomutase (PGM1) decreased in abundance in AA relative to BB sired steers, within the pathway. Other proteins identified as greater in abundance in AA compared with BB included AMP deaminase 1 (AMPD1), LIM domain binding 3 (LDB3), vinculin (VCL), capping protein $\alpha$ (CAPZA2), heat shock protein $\beta-1$ (HSPB1), and peroxiredoxin 6 (PRDX6).

\section{Effect of EPD ${ }_{\text {cwt }}$ on Protein Abundance}

No difference $(P>0.05)$ in protein spot abundance was detected between High and Low BB-sired animals. For AA, however, a difference $(P<0.012)$ in protein abundance of 3 glycolytic enzymes was observed between High and Low EPD ${ }_{\text {cwt }}$ groups. These 3 proteins, glucose-6-phosphate isomerase (GPI), enolase (ENO1), and pyruvate kinase (PKM2), were identified in the top canonical pathway, glycolysis/gluconeogenesis. These 3 proteins were greater in abundance in High compared with Low AA sired steers (Table 3).

\section{qPCR Validation of Proteomics Data}

To verify the DIGE results, a total of 3 proteins (glucose-6-phosphate isomerase, enolase-3, and pyruvate kinase) found to be differentially expressed in muscle of High vs. Low AA-sired steers were targeted to be analyzed by qPCR (Table 4). There was a statistically significant $(P<0.05)$ strong positive correlation between the protein and mRNA expression data for all 3 genes selected (Table 4).

\section{DISCUSSION}

Bovine skeletal muscle is a heterogeneous tissue comprised of several fiber types influenced by the genotype and breed of the animal (Bouley et al., 2005; Chaze et al., 2008). Additionally, its properties evolve during postnatal life and can be modified by environmental conditions (Therkildsen, 2005; Shibata et al., 2009). This study examined differences in protein abundance in $M$. longissimus lumborum in steers sired by 2 contrasting breeds of cattle (AA and $\mathrm{BB}$ ) divergent for $\mathrm{EPD}_{\mathrm{cwt}}$. These breeds were selected on the basis of their well-documented differences in 1) maturation rates (early vs. late) and 2) intramuscular fat accumulation as well as perceived meat quality differences (Kuber et al., 2004; Sadkowski et al., 2009). We have shown that metabolic enzymes involved

Table 2. Proteins differentially expressed between Belgian Blue (BB) and Aberdeen Angus (AA) sired steers

\begin{tabular}{|c|c|c|c|c|c|c|c|}
\hline No. & $\begin{array}{l}\text { Identified } \\
\text { protein }\end{array}$ & $\begin{array}{l}\text { NCBI accession no. } \\
\text { (Source) }\end{array}$ & $\begin{array}{l}\text { Mascot } \\
\text { score }\end{array}$ & $\begin{array}{c}\text { Fold } \\
\text { Change }^{1}\end{array}$ & $P$-value & $\begin{array}{c}\text { Matched peptides/sequence } \\
\text { coverage, } \%\end{array}$ & $\begin{array}{l}\text { Theoretical } \\
\mathrm{pI} / \mathrm{M}_{\mathrm{r}}, \mathrm{kDa}^{2}\end{array}$ \\
\hline \multicolumn{8}{|c|}{ Metabolic } \\
\hline 1 & PYGM & gi|73983205 (canine) & 224 & $5.7 \uparrow$ & $<0.0001$ & $6 / 10$ & $6.6 / 97.5$ \\
\hline 2 & PYGM & gi|154426116 & 1652 & $2.9 \uparrow$ & $<0.0001$ & $34 / 47$ & $6.7 / 97.5$ \\
\hline 3 & PYGM & gi|28461197 & 1374 & $2.8 \uparrow$ & $<0.0001$ & $31 / 37$ & $6.7 / 97.6$ \\
\hline 6 & PYGM & gi|28461197 & 609 & $2.0 \uparrow$ & 0.002 & $18 / 24$ & \\
\hline 4 & PGAM2 & gi|84000195 & 643 & $2.9 \uparrow$ & 0.004 & $13 / 49$ & $9.0 / 28.8$ \\
\hline 5 & PGM1 & gi|116004023 & 1029 & $2.2 \downarrow$ & 0.0001 & $21 / 52$ & $6.4 / 61.8$ \\
\hline 7 & ALDOA & gi|156120479 & 804 & $2.8 \uparrow$ & $<0.0001$ & $15 / 53$ & $8.5 / 39.9$ \\
\hline 8 & $\mathrm{ACO} 2$ & gi|74268076 & 816 & $5.3 \uparrow$ & 0.0006 & $17 / 30$ & $8.0 / 85.9$ \\
\hline 9 & $\mathrm{OGDH}$ & gi|115496742 & 491 & $3.9 \uparrow$ & 0.0001 & $12 / 12$ & $6.3 / 116.8$ \\
\hline 18 & AMPD1 & gi|154152079 & 279 & $4.0 \uparrow$ & 0.0002 & $6 / 10$ & $6.9 / 87.2$ \\
\hline \multicolumn{8}{|c|}{ Contractile apparatus } \\
\hline 10 & TNNT1 & gi|21039010 & 219 & $3.9 \uparrow$ & $<0.0001$ & $5 / 23$ & $6.2 / 30.1$ \\
\hline 11 & TNNI2 & gi|76658412 & 213 & $3.5 \uparrow$ & $<0.0001$ & $4 / 17$ & $8.9 / 21.5$ \\
\hline 19 & MYL1 & gi|1181841 & 451 & $4.6 \downarrow$ & $<0.0001$ & $8 / 52$ & $4.7 / 18.8$ \\
\hline 20 & MYLPF & gi|115497166 & 206 & $2.8 \downarrow$ & 0.003 & $5 / 31$ & $4.9 / 19.1$ \\
\hline 21 & MYLPF & gi|115497166 & 497 & $2.1 \downarrow$ & 0.005 & $9 / 61$ & \\
\hline \multicolumn{8}{|c|}{ Cell structure } \\
\hline 12 & LDB3 & gi|78369256 & 362 & $4.0 \uparrow$ & 0.003 & $7 / 33$ & $9.3 / 35.5$ \\
\hline 13 & VCL & gi|194679459 & 440 & $2.3 \uparrow$ & 0.006 & $10 / 13$ & $5.9 / 11.7$ \\
\hline 17 & VCL & gi|194679457 & 432 & $1.9 \uparrow$ & 0.003 & $10 / 10$ & $5.6 / 124.3$ \\
\hline 14 & CAPZA2 & gi|433308 (human) & 382 & $2.2 \uparrow$ & $<0.0001$ & $8 / 44$ & $5.6 / 32.9$ \\
\hline \multicolumn{8}{|c|}{ Cell defense } \\
\hline 15 & HSPB1 & gi|85542053 & 750 & $2.2 \uparrow$ & 0.0006 & $15 / 76$ & $6.0 / 22.4$ \\
\hline 16 & PRDX6 & gi|27807167 & 626 & $1.9 \uparrow$ & 0.0003 & $13 / 60$ & $6.0 / 25.1$ \\
\hline
\end{tabular}

${ }^{1}$ An up arrow $(\uparrow)=$ increased in AA- vs. BB-sired steers; a down arrow $(\downarrow)=$ decreased in AA- vs. BB-sired steers.

${ }^{2} \mathrm{p}_{\mathrm{I}}=$ isoelectric point, $\mathrm{M}_{\mathrm{r}}=$ molecular weight. 
in glycolysis, and the citric acid cycle, cell structure, and cell defense were differentially expressed in AA- vs. BBsired steers. In addition, protein abundance of glucose-6phosphate isomerase, enolase-3, and pyruvate kinase was greater in High compared with Low AA animals. This information will assist in our understanding of genetic influences controlling muscle growth and fat accumulation and could contribute to future breeding programs to increase lean tissue gain of beef cattle.

Proteomic technologies have been used to characterize protein expression of muscle (Talamo et al., 2003; Bouley et al., 2004) and to assess changes in muscle proteins postmortem (Lametsch and Bendixen, 2001; Lametsch et al., 2003). Two-dimensional gel electrophoresis (2D-GE) is one of the most commonly used techniques in proteomics (Ohlendieck, 2011). It has been shown that up to 10,000 protein spots can be separated in 1 gel, allowing high-resolution proteomic analysis (Klose and Kobalz, 1995). Two-dimensional difference gel electrophoresis (Unlü et al., 1997) addresses some of the major problems, including lack of reproducibility and quantitation, associated with traditional 2D-GE. Thus, comparative protein expression and post-translational protein modification profiling are tasks that are best performed using 2D-DIGE. This technique has recently been employed to examine quantitative and qualitative differences between fastand slow-type muscles in Holstein cows (Oe et al., 2011).

\section{Effect of Sire Breed on Protein Abundance}

The top canonical pathway identified was glycolysis/ gluconeogenesis with 3 proteins, PYGM, PGAM2, and ALDOA, found to be in greater abundance in AA compared with BB. Bernard et al. (2009) found that glycolytic enzymes were increased in bulls divergently selected for high compared with low muscle growth. However, in the current study, AA had greater abundance of proteins involved in glycolysis and the citric cycle compared with $\mathrm{BB}$, despite the greater muscularity in the latter. Results from our study and those of Bernard et al. (2009) possibly differ mainly in the intramuscular fat

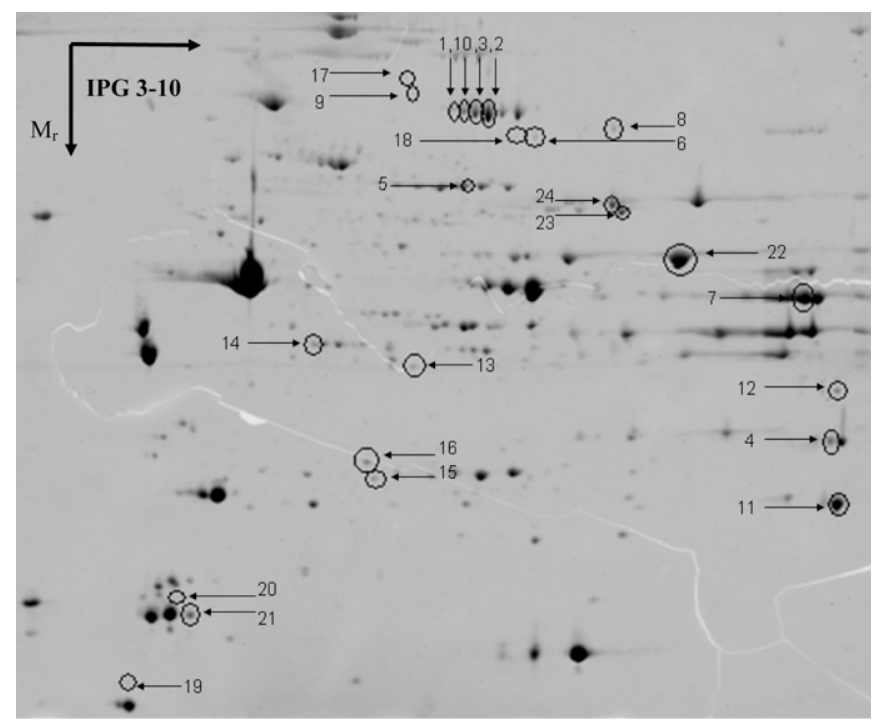

Figure 1. Representative 2-dimensional gel image of M. longissimus lumborum of crossbred steers. The proteins are indicated by spot number, which corresponds to those identified as differentially expressed between the different groups (see Tables 2 and 3).

relative to muscle in AA arising because of differences in sire breed genetics and age of the animals.

In fatty acid synthesis, the reduced form of nicotinamide adenine dinucleotide phosphate (NADPH) is required to support lipogenesis. In ruminants, 50\% to $80 \%$ of NADPH required for fatty acid synthesis in adipose tissue is produced by glucose oxidation via the pentose phosphate pathway (Vernon, 1981). Up to $50 \%$ of NADPH used in fatty acid synthesis is also generated via decarboxylation of isocitrate to $\alpha$-ketoglutarate (isocitrate dehydrogenase pathway; Vernon, 1981; Nafikov and Beitz, 2007). This action is preceded by the activity of the enzyme ACO2 and followed by a reaction involving the enzyme OGDH. These enzymes, which were increased in AA compared with BB steers in the current study, are involved in the citric acid cycle, the third canonical pathway identified to be activated. This suggests greater protein abundance of enzymes relating to oxidative metabolism in AA-sired steers. As there are also greater quantities of mitochondria, where the citric acid cycle takes place, in slow-twitch compared with fast-twitch muscle fibers as evident in AA, this finding is not surprising and warrants

Table 3. Proteins differentially expressed in muscle tissue between Aberdeen Angus-sired steers of either High or Low for sire expected progeny difference for carcass weight $\left(\mathrm{EPD}_{\mathrm{cwt}}\right)$

\begin{tabular}{|c|c|c|c|c|c|c|c|}
\hline No. & $\begin{array}{l}\text { Identified } \\
\text { protein }\end{array}$ & $\begin{array}{l}\text { NCBI accession no. } \\
\text { (Source) }\end{array}$ & Mascot score & Fold change $^{1}$ & $P$-value & $\begin{array}{c}\text { Matched peptides/sequence } \\
\text { coverage, } \%\end{array}$ & $\begin{array}{c}\text { Theoretical pI/ } \\
\mathrm{M}_{\mathrm{r}}, \mathrm{kDa}^{2}\end{array}$ \\
\hline \multicolumn{8}{|c|}{ Metabolic } \\
\hline 22 & ENO3 & gi|87196501 (Canis) & 1117 & $1.5 \uparrow$ & $<0.0001$ & $21 / 50$ & $7.6 / 47.5$ \\
\hline 23 & GPI & gi|94966765 & 646 & $1.8 \uparrow$ & 0.003 & $13 / 24$ & $7.3 / 63.0$ \\
\hline 24 & PKM2 & gi|73587283 & 894 & $1.7 \uparrow$ & 0.012 & $14 / 34$ & $8.6 / 62.0$ \\
\hline
\end{tabular}

${ }^{1}$ An up arrow $(\uparrow)=$ increased in High compared with Low for $\mathrm{EPD}_{\mathrm{cwt}}$

${ }^{2} \mathrm{p}_{\mathrm{I}}$ = isoelectric point, $\mathrm{M}_{\mathrm{r}}=$ molecular weight. 


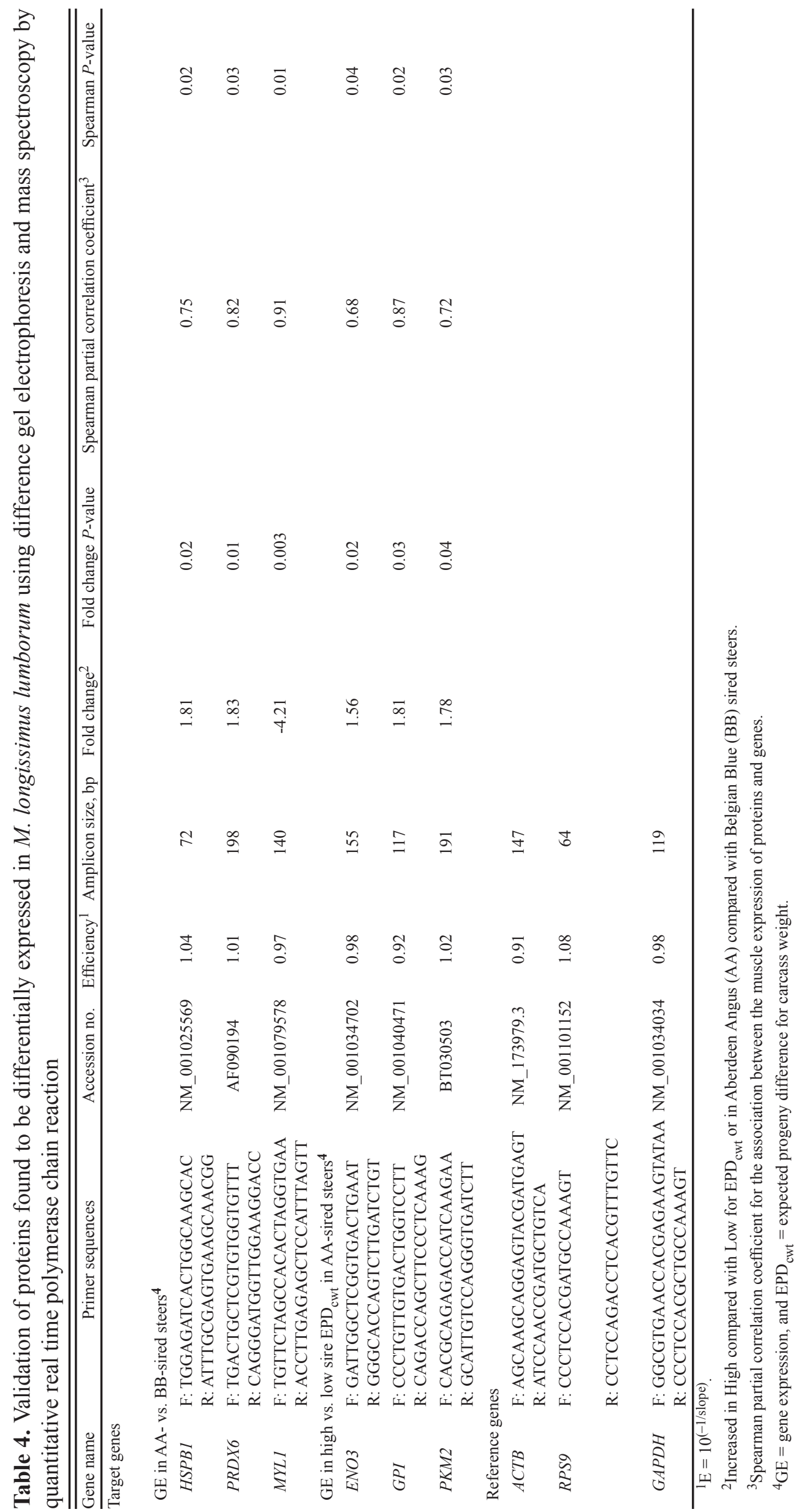

further investigation. This study reveals that different metabolic actions are taking place in the muscle tissue that directly relate to sire breed type in cattle. Intramuscular fat accumulation may be associated with increased abundance of enzymes relating to glycolysis, and the current research is consistent with these findings (Murgiano et al., 2010; Sieczkowska et al., 2010).

Glucose-1-phosphate is converted to glucose6-phosphate during glycogen breakdown by phosphoglucomutase (PGM1), allowing it entry into the glycolytic pathway (McMurry and Begley, 2005). Alternatively, this enzyme can also function in reverse, facilitating glycogen synthesis. A 2.2fold increase was observed in the expression of the PGM protein for $\mathrm{BB}$ compared with AA cattle. The activity of PGM can be attributed to that of at least 2 closely related isoforms (PGM1 and PGM2) encoded by different genes (Oh and Hopper, 1990). Consistent with our results, Hamelin et al. (2006) reported that muscle hypertrophy in the ovine is associated with an upregulation of enzymes involved in glycolytic metabolism together with oxidative metabolism in LM. They also showed that protein abundance of PGM1 and PGM2 was increased in rams with muscular hypertrophy compared with conventional genotypes (Hamelin et al., 2006). Muscular hypertrophy, or "double" muscling, occurs because of 
mutations in the myostatin coding sequence, resulting in the production of a truncated protein (McPherron et al., 1997). Bouley et al. (2005) found that heterozygote and homozygote animals had a greater proportion of fasttwitch glycolytic fibers in muscle, resulting in differences in protein expression. Therefore, the myostatin deletion was consistent with an increased fast muscle phenotype (Bouley et al., 2005) and reduced slow-twitch oxidative fibers (Keane and Moloney, 2010). Fast-twitch glycolytic fibers, also referred to as white fibers, store high quantities of glycogen (Sherwood and Wagers, 2006). As it is known that PGM plays a role in glycogen catabolism as well as glycogen synthesis (Penha et al., 2005) and given that BB have a greater number of fast-twitch fibers, PGM may function in either glycogen synthesis or breakdown in muscle fibers of BB-sired progeny. However, further research is warranted to investigate the exact role of PGM in muscle of BB-sired compared with AA-sired animals.

The second canonical pathway identified in the current study was the PKA signaling pathway that incorporated proteins such as MYL1, MYLPF, and TNNI2. This pathway is central to many functions in the cell as well as playing a role in cytoskeleton regulation. Belgian Blue have large numbers of fast-twitch fibers because of the myostatin deletion (Bouley et al., 2005). One of the main molecular indicators of fast glycolytic fiber type is fast-twitch myosin (MYL1; Lehnert et al., 2006). Therefore, it is not surprising that in our study MYL1 protein expression was decreased in AA-sired steers relative to BB. In the study of Murgiano et al. (2010), LM from 2 distinct pig breeds, Casertana and Large White, were compared. Proteins related to MYL1 were increased in Large White, a breed that excels in growth of lean muscle tissue, consistent with our data for BB cattle. Troponin $\mathrm{T}$ ( $\mathbf{T n T}$ ) is an important regulatory and structural component of skeletal muscle thin filaments (Perry, 1998). Troponin T type 1 (TNNT1) and TNNI2, found in slow- and fast-twitch skeletal muscle, respectively, are involved in muscle contraction (Picard et al., 2010) and were increased in expression in AA-sired relative to BBsired steers. Sadkowski et al. (2008) found that TNNT1 was a potential myostatin-dependent gene possibly explaining the differential expression in its protein product in AAsired relative to BB-sired steers. In double-muscled animals, proteomics studies have demonstrated the underexpression of slow TnT isoforms and the overexpression of fast TnT isoforms in fast glycolytic muscles (Picard et al., 2010) and could potentially explain differences observed in the expression of these proteins in the current study due to sire breed. Furthermore, in postmortem bovine muscle, a 30or 32-kDa peptide, which was immunologically identified as a TnT fragment, is the first degradation product of a skeletal muscle component that is associated with meat tenderness (Olson and Parrish, 1977). The degradation of TnT progresses simultaneously with the postmortem tenderization of beef, indicating a strong correlation between the 2 events (Penny and Dransfield, 1979). As AA is an early-maturing breed associated with beef tenderness (Kuber et al., 2004), it is not surprising that isoforms of TnT were present in greater abundance in muscle of the AA-sired compared with BB-sired steers.

In the current study, heat shock protein (HSP) $\beta-1$ and peroxiredoxin 6 (PRDX6), involved in cell defense, were increased in AA-sired relative to BB-sired steers. Heat shock proteins are essential for normal cellular stress responses. Heat shock protein $\beta-1$ is a relatively small $(27 \mathrm{kDa})$ molecular chaperone protein associated with cellular development, differentiation, and signal transduction, and a microarray analysis revealed that mRNA expression of HSP $\beta 1$ increased during the intramuscular fat development stage in cattle (Wang et al., 2009). Zhang et al. (2010) found that HSP $\beta 1$ increased during fat accumulation in bovine skeletal muscle. This is consistent with the fact that AA-sired steers have greater intramuscular fat compared with their BB-sired contemporaries, which was confirmed by chemical analysis of muscle tissue in the current study. Recently, Zhang et al. (2012) found that protein expression and mRNA expression of HSP $\beta 1$ was upregulated in skeletal muscle tissue in response to differentiation, playing an important role in myogenesis, indicating that muscle tissue in AA-sired steers, an early-maturing breed relative to $\mathrm{BB}$, was possibly at a more advanced stage of development. Peroxiredoxin 6, a member of antioxidant protein superfamily, plays an important role in oxidative stress, catabolism of lipids, and phospholipid liposomes (Fisher, 2011). There is little information in the literature on protein or mRNA expression of PRDX6 in cattle, and this is the first published study to show the protein expression of PRDX6 in bovine skeletal muscle. It may be hypothesized that as AA-sired steers contain greater proportions of intramuscular fat compared with BB-sired steers, an increase in PRDX6 is required for lipid catabolism. In addition, 2 SNP in Prdx6 have been shown to be associated with meat quality traits (especially the muscle tenderness; Liu et al., 2011). This is not surprising, considering that meat from AA has been shown to be positively associated with having increased tenderness and flavor (Kuber et al., 2004).

\section{Effect of EPD ${ }_{\text {cwt }}$ on Protein Abundance}

The glycolytic pathway provides cells with metabolic precursors and a rapid source of energy (Murgiano et al., 2010). The results of the current study show that within AA, a statistically significant difference in enzymes relating to glycolysis and gluconeogenesis was observed between

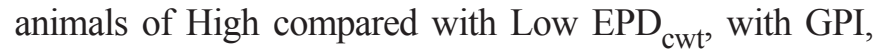
ENO3, and PKM2 exhibiting increased protein expression 
in AA-High compared with AA-Low animals. Bernard et al. (2009) examined the effects of genetic selection in favor of increased muscle growth on gene expression in the muscle of young Charolais bulls using microarray technology. Consistent with our findings, the authors reported that gene expression of GPI and ENO3 was increased in bulls of High compared with Low muscle growth. In addition, it has been established that animals undergoing accelerated muscle growth (e.g., compensatory growth) exhibit greater gene and protein abundance of GPI, ENO3, and PKM2 (Lametsch et al., 2006; Lehnert et al., 2006). Teltathum and Mekchay (2009) and Doherty et al. (2004) reported that during pectoralis muscle growth in chickens, enzymes relating to the glycolytic pathway (ENO3 and PKM2) were greater in abundance during a growth phase compared with at hatching. In ovine studies, Hamelin et al. (2006) reported that the protein abundance of ENO3 and PKM2 was greater in the LM of fast-growing compared with slow-growing rams. These findings indicate that in AA increased muscle growth potential may be associated with increased glycolysis and, in the case of Bernard et al. (2009), decreased oxidative metabolism.

In contrast to our findings for $\mathrm{AA}$, no effect of $\mathrm{EPD}_{\mathrm{cwt}}$ on protein abundance was detected in $\mathrm{BB}$ animals. This result is consistent with the performance data for these animals, reported by Campion et al. (2009a), where no difference in growth rate or carcass weight between BB-

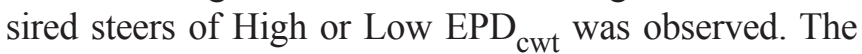
authors of that study proposed that the absence of an effect of genetic merit on growth rate in BB steers may be associated with the fact that these animals are crossbred from HF cows and are heterozygous for the mutation in the myostatin gene, whereas $\mathrm{EPD}_{\text {cwt }}$ values are calculated on the basis of performance data from both crossbred and purebred (heterozygous and homozygous for the mutation in the myostatin gene, respectively) animals.

We have provided evidence for different metabolic processes taking place in muscle of crossbred AAand BB-sired steers that are specific to breed type. Aberdeen Angus, an early-maturing breed, accumulates intramuscular fat at an earlier age, whereas late-maturing breeds like $\mathrm{BB}$ continue growing to a heavier mature weight. Proteins related to fiber type were increased in BB-sired steers, with proteins involved in glycolysis and the citric acid cycle in greater abundance in the muscle of AA-sired animals. In addition, this study facilitated greater insight into differential muscle proteome expression across bovine breeds divergently selected for muscle growth rate potential, with proteins involved in glycolysis increased in AA-sired steers of High compared with Low genetic merit for carcass growth.

Skeletal muscle is a very heterogeneous tissue consisting of diverse cell types. Intramuscular fat in bovine muscle is primarily accumulated and stored within adipocytes located in connective tissue between bundles of muscle fibers (Harper and Pethick, 2004). As differences exist in fat accumulation between BB- and AA-sired steers, the authors took care during tissue collection to harvest lean muscle tissue only, avoiding intramuscular fat. In addition the protocol used in this study was optimized for protein extraction from muscle tissue (Mullen et al., 2011; Donoghue et al., 2010). There is also no evidence of differential expression of markers of fat metabolism between the AA- and BB-sired steers in the current study. Although technologies such as laser microdissection (Albrecht et al., 2011) further enhance the ability to isolate myocytes, it is expensive and laborious and was beyond the scope of this study.

Data from this study will aid in our understanding of genetic influences controlling muscle growth and fat accumulation, and future work will continue to examine the potentiating or inhibitory effects of sire breed and $\mathrm{EPD}_{\mathrm{cwt}}$ at more critical time points during the growth phase of the animal to elucidate key proteins regulating muscle growth. Glycolytic enzymes are potential candidates for high muscle growth for future investigation, including exploration of SNP. After appropriate validation, these markers could be incorporated into future cattle breeding programs to improve the accuracy of selection for muscle growth.

\section{LITERATURE CITED}

Albrecht, E., T. Gotoh, F. Ebara, J. Wegner, and S. Maak. 2011. Technical note: Determination of cell-specific gene expression in bovine skeletal muscle tissue using laser microdissection and reversetranscription quantitative polymerase chain reaction. J. Anim. Sci. 89:4339-4343.

Amaral, L. A. N., A. Díaz-Guilera, A. A. Moreira, A. L. Goldberger, and L. A. Lipsitz. 2004. Emergence of complex dynamics in a simple model of signaling networks. Proc. Natl. Acad. Sci. U. S. A. 101:15551-15555.

Bernard, C., I. Casser-Malek, G. Renand, and J. F. Hocquette. 2009. Changes in muscle gene expression related to metabolism according to growth potential in young bulls. Meat Sci. 82: 205212.

Bouley, J., C. Chambon, and B. Picard. 2004. Mapping of bovine skeletal muscle proteins using two-dimensional gel electrophoresis and mass spectrometry. Proteomics 4:1811-1824.

Bouley, J., B. Meunier, C. Chambon, S. De Smet, J. F. Hocquette, and B. Picard. 2005. Proteomic analysis of bovine skeletal muscle hypertrophy. Proteomics 5:490-500.

Campion, B., M. G. Keane, D. A. Kenny, and D. Berry. 2009a. Evaluation of the estimated genetic merit for carcass weight in beef cattle: Live weights, feed intake, body measurements, skeletal and muscular scores, and carcass characteristics. Livest. Sci. 126: 87-99.

Campion, B., M. G. Keane, D. A. Kenny, and D. Berry. 2009b. Evaluation of the estimated genetic merit for carcass weight in beef cattle: Blood metabolites, carcass measurements, carcass composition and selected non-carcass components. Livest. Sci. 126:100-111. 
Chaze, T., B. Meunier, C. Chambon, C. Jurie, and B. Picard. 2008. In vivo proteome dynamics during early bovine myogenesis. Proteomics 8:4236-4248.

Crews, D. H., Jr., E. J. Pollak, and R. L. Quaas. 2004. Evaluation of Simmental carcass EPD estimated using live and carcass data. J. Anim. Sci. 82:661-667.

Doherty, M. K., L. McLean, J. R. Hayter, J. M. Pratt, D. H. Robertson, A. El-Shafei, S. J. Gaskell, and R. J. Beynon. 2004. The proteome of chicken skeletal muscle: Changes in soluble protein expression during growth in a layer strain. Proteomics 4:2082-2093.

Donoghue, P., L. Staunton, E. Mullen, G. Manning, and K. Ohlendieck. 2010. DIGE analysis of rat skeletal muscle proteins using nonionic detergent phase extraction of young adult versus aged gastrocnemius tissue. J. Proteomics 73(8):1441-1453.

Doran, P., G. Martin, P. Dowling, H. Jockusch, and K. Ohlendieck. 2006. Proteome analysis of the dystrophin-deficient MDX diaphragm reveals a drastic increase in the heat shock protein cvHSP. Proteomics 6:4610-4621.

Fiems L. O., J. L. De Boever., J. M. Vanacker and D. L De Brabander. 2013. Effect of cull potatoes in the diet for finishing Belgian Blue double-muscled cows. Animal 7:93-100.

Fisher, A. B. 2011. Peroxiredoxin 6: A bifunctional enzyme with glutathione peroxidase and phospholipase A activities. Antioxid. Redox Signal. 15:831-844.

Greenbaum, D., C. Colangelo, K. Williams, and M. Gerstein. 2003. Comparing protein abundance and mRNA expression levels on a genomic scale. Genome Biol. 4:117.

Hamelin, M., T. Sayd, C. Chambon, J. Bouix, B. Bibé, D. Milenkovic, H. Leveziel, M. Georges, A. Clop, P. Marinova, and E. Laville. 2006. Proteomic analysis of ovine muscle hypertrophy. J. Anim. Sci. 84:3266-3276.

Harper, G. S., and D. W Pethick. 2004. How might marbling begin? Aust. J. Exp. Agric. 44:653-662.

Higuchi, R., C. Fockler, G. Dollinger, and R. Watson 1993. Kinetic PCR analysis: Real-time monitoring of DNA amplification reactions. Nat. Biotechnol. 11:1026-1030.

Karp, N. A., and K. S. Lilley. 2005. Maximising sensitivity for detecting changes in protein expression: Experimental design using minimal CyDyes. Proteomics 5:3105-3115.

Keady, S. M., D. A. Kenny, M. G. Keane, and S. M. Waters. 2011. Effect of sire breed and genetic merit for carcass weight on the transcriptional regulation of the somatotropic axis in $M$. longissimus dorsi of crossbred steers. J. Anim. Sci. 89: 4007-4016.

Keane, M. G., P. G. Dunne, D. A. Kenny, and D. P. Berry. 2011. Effects of genetic merit for carcass weight, breed type and slaughter weight on performance and carcass traits of beef $\times$ dairy steers. Animal 5:182-194.

Keane, M. G., and A. P. Moloney. 2010. Comparison of pasture and concentrate finishing of Holstein-Friesian, Aberdeen Angus $\times$ Holstein-Friesian and Belgian Blue $\times$ Holstein-Friesian steers. Ir. J. Agric. Food Res. 49:11-26.

Klose, J., and U. Kobalz. 1995. Two-dimensional electrophoresis of proteins: An updated protocol and implications for a functional analysis of the genome. Electrophoresis 16:1034-1059.

Kuber, P. S., J. R. Busboom, S. K. Duckett, P. S. Mir, Z. Mir, R. J. McCormick, C. T. Gaskins, J. D. Cronrath, D. J. Marks, and J. J. Reeves. 2004. Effects of biological type and dietary fat treatment on factors associated with tenderness: II. Measurements on beef semitendinosus muscle. J. Anim. Sci. 82:779-784.

Lametsch, R., and E. Bendixen. 2001. Proteome analysis applied to meat science: Characterizing postmortem changes in porcine muscle. J. Agric. Food Chem. 49:4531-4537.
Lametsch, R., A. Karlsson, K. Rosenvold, H. J. Andersen, P. Roepstorff, and E. Bendixen. 2003. Postmortem proteome changes of porcine muscle related to tenderness. J. Agric. Food Chem. 51:6992-6997.

Lametsch, R., L. Kristensen, M. R. Larsen, M. Therkildsen, N. Oksbjerg, and P. Ertbjerg. 2006. Changes in the muscle proteome after compensatory growth in pigs. J. Anim. Sci. 84:918-924.

Lehnert, S. A., K. A. Byrne, A. Reverter, Y. Wang, G. S. Nattrass, N. J. Hudson, and G. S. Harper. 2006. Gene expression profiling of bovine skeletal muscle in response to and during recovery from chronic and severe undernutrition. J. Anim Sci. 84:3239-3250.

Livak, K. J., and T. D. Schmittgen. 2001. Analysis of relative gene expression data using real-time quantitative PCR and the $2^{-\Delta \Delta C T}$ Method. Methods. 25:402-408.

Liu, Y., W. J. Wu, B. Zuo, Z. Q. Ren, and Y. Z. Xiong. 2011. Polymorphism in coding region of pig PRDX6 gene and its genetic effects analysis. Yi Chuan. 33:743-748.

McCabe, M. S., S. M. Waters, D. G. Morris, D. A. Kenny, D. J. Lynn, and C. J. Creevey. 2012. RNA-seq analysis of differential gene expression in liver from lactating dairy cows divergent in negative energy balance. BMC Genomics 13:193.

McMurry, J., and T. Begley. 2005. The Organic Chemistry of Biological Pathways. Roberts and Company, Englewood, CO.

McPherron, A. C., A. M. Lawler, and S.-J. Lee. 1997. Regulation of skeletal muscle mass in mice by a new TGF-p superfamily member. Nature 387:83-90.

Mullen, E., E. O’Reilly, and K. Ohlendieck. 2011. Skeletal muscle tissue from the Goto-Kakizaki rat model of type-2 diabetes exhibits increased levels of the small heat shock protein Hsp27. Mol. Med. Report. 4:229-36.

Murgiano, L., A. D’Alessandro, M. G. Egidi, A. Crisa, G. Prosperini, A. M. Timperio, A. Valentini, and L. Zolla. 2010. Proteomics and transcriptomics investigation on longissimus muscles in Large White and Casertana pig breeds. J. Proteome Res. 9:6450-6466.

Nafikov, R.A., and D. C. Beitz. 2007. Carbohydrate and lipid metabolism in farm animals. J. Nutr. 137:702-705.

O'Connell, K., and K. Ohlendieck. 2009. Proteomic DIGE analysis of the mitochondria-enriched fraction from aged rat skeletal muscle. Proteomics 9:5509-5524.

Oe, M., M. Ohnishi-Kameyama, I. Nakajima, S. Muroya, M. Shibata, K. Ojima, S. Kushibiki, and K. Chikuni. 2011. Proteome analysis of whole and water-soluble proteins in masseter and semitendinosus muscles of Holstein cows. Anim. Sci. J. 82:181-186.

Oh, D., and J. E. Hopper. 1990. Transcription of a yeast phosphoglucomutase isozyme gene is galactose inducible and glucose repressible. Mol. Cell Biol. 10:1415-1422.

Ohlendieck, K. 2011. Skeletal muscle proteomics: Current approaches, technical challenges and emerging techniques. Skelet. Muscle 1:6.

Olson, D. G., and F. C. Parrish Jr. 1977. Relationship of myofibril fragmentation index to measure of beefsteak tenderness. J. Food Sci. 42:506-509.

Penha, L. L., L. Mendonça-Previato, J. O. Previato, J. Scharfstein, N. Heise, and A. P. Lima. 2005. Cloning and characterization of the phosphoglucomutase of Trypanosoma cruzi and functional complementation of a Saccharomyces cerevisiae PGM null mutant. Glycobiology 15:1359-1567.

Penny, I. F., and E. Dransfield. 1979. Relationship between toughness and troponin $\mathrm{T}$ in conditioned beef. Meat Sci. 3:135-141.

Perry S. V. 1998. Troponin T: genetics, properties and function. J Muscle Res Cell Motil.19:575-602.

Picard, B., C. Berri, L. Lefaucheur, C. Molette, T. Sayd, and C. Terlouw. 2010. Skeletal muscle proteomics in livestock production. Brief Funct. Genomics 9:259-278. 
Rogers, S., M. Girolami, W. Kolch, K. M. Waters, T. Liu, B. Thrall, and H. S. Wiley. 2008. Investigating the correspondence between transcriptomic and proteomic expression profiles using coupled cluster models. Bioinformatics. 24:2894-2900.

Sadkowski, T., M. Jank, L. Zwierzchowski, J. Oprzadek, and T. Motyl. 2009. Comparison of skeletal muscle transcriptional profiles in dairy and beef breeds bulls. J. Appl. Genet. 50:109-123.

Sadkowski, T., M. Jank, L. Zwierzchowski, E. Siadkowska, J. Oprzadek, and T. J. Motyl. 2008. Gene expression profiling in skeletal muscle of Holstein-Friesian bulls with single-nucleotide polymorphism in the myostatin gene 5'-flanking region. Appl. Genet. 49:237-250.

Shibata, M., K. Matsumoto, M. Oe, M. Ohnishi-Kameyama, K. Ojima, I. Nakajima, S. Muroya, and K. Chikuni. 2009. Differential expression of the skeletal muscle proteome in grazed cattle. J. Anim. Sci. 87:2700-2708.

Sherwood, R. I., and A. J. Wagers. 2006. Harnessing the potential of myogenic satellite cells. Trends Mol. Med. 12:189-192.

Sieczkowska, H., A. Zybert, E. Krzęcio, K. Antosik, M. KoćwinPodsiadła, M. Pierzchała, and P. Urbański. 2010. The expression of genes PKM2 and CAST in the muscle tissue of pigs differentiated by glycolytic potential and drip loss, with reference to the genetic group. Meat Sci. 84:137-142.

Talamo, F., C. D’Ambrosio, S. Arena, P. Del Vecchio, L. Ledda, G. Zehender, L. Ferrara, and A. Scaloni. 2003. Proteins from bovine tissues and biological fluids: Defining a reference electrophoresis map for liver, kidney, muscle, plasma and red blood cells. Proteomics 4:440-460.
Teltathum, T., and S. Mekchay. 2009. Proteome changes in Thai indigenous chicken muscle during growth period. Int. J. Biol. Sci. 5:679-685.

Therkildsen, M. 2005. Muscle protein degradation in bull calves with compensatory growth. Livest. Prod. Sci. 98:205-218.

Unlü, M., M. E. Morgan, and J. S. Minden. 1997. Difference gel electrophoresis: A single gel method for detecting changes in protein extracts. Electrophoresis 18:2071-2077.

Vernon, R. G. 1981. Lipid metabolism in the adipose tissue of ruminant animals. Pages 279-362 in Lipid Metabolism in Ruminant Animals. W. W. Christie, ed. Pergamon Press, Oxford.

Wang, Y. H., N. I. Bower, A. Reverter, S. H. Tan, N. De Jager, R. Wang, S. M. McWilliam, L. M. Café, P. L. Greenwood, and S. A. Lehnert. 2009. Gene expression patterns during intramuscular fat development in cattle. J. Anim. Sci. 87:119-130.

Zhang, Q., H. G. Lee, J. A. Han, S. K. Kang, N. K. Lee, M. Baik, and Y. J. Choi. 2012. Differentially expressed proteins associated with myogenesis and adipogenesis in skeletal muscle and adipose tissue between bulls and steers. Mol. Biol. Rep. 39:953-960.

Zhang, Q., H. G. Lee, J. A. Han, E. B. Kim, S. K. Kang, J. Yin, M. Baik, Y. Shen, S. H. Kim, K. S. Seo, and Y. J. Choi. 2010. Differentially expressed proteins during fat accumulation in bovine skeletal muscle. Meat Sci. 86:814-820.

Zhao, C., F. Tian, Y. Yu, J. Luo, A. Mitra, F. Zhan, Y. Hou, G. Liu, L. Zan, M. S. Updike, and J. Song. 2012. Functional genomic analysis of variation on beef tenderness induced by acute stress in Angus cattle. Comp. Funct. Genomics 2012:756284. 